\title{
Sujeito ou demandante? Reflexões sobre o caráter da participação nos conselhos comunitários de segurança de São Paulo
}

\section{Resumo}

O artigo tem por objetivo analisar atitudes, valores e crenças de policiais militares relacionados à participação social em espaços institucionalmente fomentados pelo poder público do Estado de São Paulo e explorar os fatores que limitam ou favorecem a participação dos cidadãos. A participação do cidadão nesses espaços foi analisada a partir da sua inserção nas instituições participativas, as quais compreendemos como instâncias da esfera pública que reúnem cidadãos em consultas ou deliberações públicas organizadas de maneira autoconsciente (Fung; Wright, 2001). Dentro dessa perspectiva, buscou-se compreender as dinâmicas de funcionamento e as interações entre cidadãos e agentes públicos de cinco conselhos comunitários de segurança pública (Consegs) existentes do espaço territorial do município de São Paulo.

Palavras-chave: Instituições Participativas. Conselhos Comunitários de Segurança. Polícia Militar.

\footnotetext{
*Fundação Getúlio Vargas (Brasil)
} 


\section{Subject or demanding citizen? Reflections on how participa- tion is shaped in public security community councils in the city of São Paulo.}

\section{Abstract}

This article aims to analyze attitudes, values and beliefs of military police officers regarding the engagement of society at large on participatory institutions created by the government of the state of São Paulo and to explore key factors that inhibit or foster citizens' participation. The engagement of citizens was analyzed from their insertion on such participatory institutions, which are here understood as instances of the public sphere that gather citizens for self-consciously organized public consultations or deliberations (Fung; Wright, 2001). From that perspective, we aim to understand the dynamics of functioning and interactions between citizens and public workers on five community councils of public security (Conselhos Comunitários de Segurança - Consegs) located in the territory of the city of São Paulo.

Keywords: Participatory Institutions. Community Councils of Public Security. Military Police. 


\section{Introdução ${ }^{1}$}

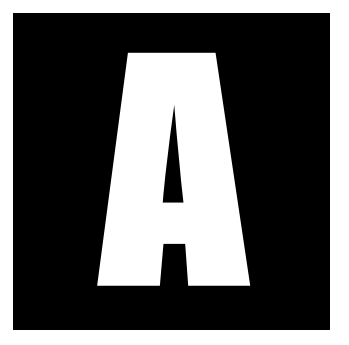

redemocratização brasileira, que se iniciou em meados dos anos de 1980, trouxe consigo a ideia da participação popular nos processos políticos como um valor intrínseco ao adensamento e consolidação da democracia no país. Isso foi ocorrendo como resultado do amadurecimento da sociedade civil, que veio se fortalecendo na oposição ao regime militar e na ampliação da reivindicação de maior protagonismo junto as diferentes instâncias do Estado, que se iniciou com a atuação de movimentos sociais urbanos ainda na década de 1970 (Sader, 1988).

Segundo Martins (2013), a participação estava na "moda" e a Carta Magna democrática de 1988 previu o direito da sociedade de articular com os órgãos de governo a formulação, implementação e acompanhamento das políticas públicas, colocando em pauta a participação popular na gestão e no controle da administração pública (p. 185). Nesse contexto, foram desenvolvidos de forma incremental, no cenário político nacional, conselhos consultivos ou deliberativos em diferentes áreas temáticas e espaços de participação popular fomentados pelo poder público, cuja missão era servir como um canal de comunicação entre o Estado e a sociedade, onde todos assumiriam a tarefa de propor, negociar e fiscalizar a realização do interesse público.

\footnotetext{
${ }^{1}$ Este artigo foi desenvolvido a partir de pesquisa realizada no âmbito da Chamada Pública IPEA/ PROREDES no 001/2011 assinada entre o Instituto de Pesquisa Econômica Aplicada e o Fórum Brasileiro de Segurança Pública para execução da pesquisa "Instituições participativas no âmbito da segurança pública brasileira: programas impulsionados por organizações policiais".
} 
Para Martins é especialmente importante demarcar a distinção entre os conselhos, surgidos a partir do final dos anos de 1980, e os chamados "movimentos sociais". Isso porque enquanto os movimentos sociais são espaços que nascem diretamente dos espaços populares, os conselhos que passam a surgir no país nesse período são instrumentos criados pelo Estado, de modo que a participação nesses espaços assume uma característica específica, regulamentada, o que a autora chama de "domesticação". Nessa perspectiva, "participar" nesses espaços significa se apropriar de um vocabulário e gramática específicos, algo que até então era considerado como monopólio do Estado e cujo acesso era restrito a uma elite mais próxima do processo decisório em diferentes políticas públicas. Nem mesmo conselhos já considerados de longa vida, como os de Saúde, que já existiam antes dos anos 1980, haviam adquirido tanta importância enquanto canais institucionalizados de conexão da sociedade com o Estado, como passou a ocorrer com esses espaços institucionalizados, com o processo de nossa recente redemocratização.

A explicação para a consolidação desse modelo de participação estaria diretamente ligada ao processo de desenvolvimento da cidadania no Brasil, muito discutida por autores como Wanderley Guilherme dos Santos (1987), José Murilo de Carvalho (2001) e Guilhermo O'Donnell (1998). Para esses autores, a cidadania no Brasil teve uma evolução histórica que difere do modelo descrito por Marshall (1967), para quem a noção de cidadania foi construída em um processo que tem início com a conquista dos direitos civis no século XVIII, seguido da conquista dos direitos políticos no século XIX e culminando com a conquista dos direitos sociais no século XX. Na perspectiva de Marshall, a conquista dos direitos civis constitui a chave para a consolidação da igualdade como base legal para a organização da sociedade e para o fim da estratificação. 
Contudo, diversos autores defendem que, no caso brasileiro, essa "ordem" foi alterada, o que impediu o estabelecimento dos direitos civis para parcela significativa da população (O'Donnell, 1998; Carvalho, 2001; Santos, 1987; Martins, 2013). Assim, o Estado forjou-se como compensador de desigualdades, sendo aquele que deveria conceder direitos ainda não adquiridos. Do mesmo modo que os direitos sociais foram apresentados como "benesses" oferecidas pelo Estado, os direitos civis e políticos também o foram. Nesse sentido, coube aos atores estatais abrir espaço para a participação do cidadão na "coisa pública", monopólio estatal até então. As instâncias de participação provocadas pelo Estado surgiram, portanto, como espaços de interlocução com a sociedade, mas nos quais a natureza e o modo de participação eram claramente induzidos e delimitados previamente (Martins, 2013, p. 200).

Todavia, se as primeiras instâncias de participação nessa nova configuração, em áreas de políticas públicas já tradicionais, como a saúde e a educação, surgiram na esteira do processo de redemocratização, a inclusão da sociedade no campo das políticas de segurança pública foi bem tardia. Apesar de a Constituição Federal de 1988 ter definido que a participação e a iniciativa popular na gestão das políticas deveriam ser práticas e valores adotados pelo Estado, o direito à segurança não foi mencionado como um dos temas em que devesse ocorrer o estabelecimento de conselhos ou instâncias participativas. Essa mesma Constituição manteve intocado o artigo 144, que trata da segurança pública. Nessa direção, a exclusão da segurança pública do rol de temas sobre os quais a população deveria ser consultada relaciona-se ao histórico distanciamento da matéria em relação aos cidadãos, fundado na percepção de que a segurança pública seria muito mais uma faculdade do Estado do que um direito social. ${ }^{2}$

${ }^{2}$ Cabe lembrar, por exemplo, que a I Conferência Nacional de Segurança Pública só ocorre no ano de 2009, 21 anos após a promulgação da Constituição Federal que reinaugura a democracia no país. 
A partir da reflexão sobre a participação nos conselhos comunitários de segurança, espaços institucionalmente fomentados pelo poder público, este artigo tem por objetivo analisar atitudes, valores e crenças de policiais militares relacionados à participação social nos conselhos comunitários de segurança (Consegs) do município de São Paulo, procurando compreender os fatores que limitam ou favorecem a participação dos cidadãos.

A participação do cidadão nesses espaços foi analisada a partir da sua inserção nas instituições participativas, as quais compreendemos como instâncias da esfera pública que reúnem cidadãos em consultas ou deliberações públicas organizadas de maneira autoconsciente (Fung;Wright, 2001). As instituições participativas constituem espaços diferentes da autorização via representação clássica na teoria da ciência política (Avritzer, 2007), ampliando os canais de intervenção dos cidadãos junto às diferentes políticas públicas e, também, nos diferentes espaços estatais.

$\mathrm{O}$ artigo está dividido em seis partes, além desta introdução. $\mathrm{Na}$ sequência, apresentamos uma breve descrição da metodologia; na terceira parte, expomos descrição das normativas e decretos que regulam o funcionamento dos Consegs; na quarta parte, apresentamos relato das dinâmicas de funcionamento dos Consegs, explorando a relação entre seus participantes e os operadores das polícias; na quinta, tecemos reflexão sobre quem participa desses espaços; e, por fim, a conclusão.

\section{Metodologia}

Em termos metodológicos, a pesquisa realizada tem caráter transversal e se propôs a compreender a percepção de policiais com relação às instâncias participativas no campo da segurança pública, mais especificamente os conselhos comunitários de segurança e seus participantes, os fatores que limitam a participação dos cidadãos nesses espaços, bem como a qualidade da participação. 
Para sua operacionalização, partimos de ampla revisão bibliográfica, análise documental e coleta e tabulação de estatísticas e dados secundários dos distritos policiais do município de São Paulo. A partir da escolha dos territórios, foram realizadas observações de campo durante sete meses nas reuniões dos conselhos comunitários dos bairros de Brasilândia (localizado na área do 45음 Distrito Policial - DP), Butantã (localizado na área do 510 DP), Heliópolis (localizado na área do 95을), Itaim Bibi (localizado na área do 15음) e Santa Cecília (localizado na área do 770 DP), bem como análise das atas das reuniões acompanhadas.

A escolha dos territórios estudados foi feita com base nos indicadores criminais e socioeconômicos, de modo a oferecer um panorama representativo e heterogêneo da cidade de São Paulo. Desse modo, enquanto Brasilândia e Heliópolis são bairros periféricos, com altos indicadores de criminalidade, especialmente letal, o bairro do Butantã é um bairro de classe média, com dinâmica mais frequente de crimes contra o patrimônio. O bairro do Itaim Bibi, por sua vez, é um bairro de classe média alta, e o de Santa Cecília localiza-se na região central da capital e abarca a região conhecida como cracolândia. Adicionalmente, foram realizadas 22 entrevistas com roteiro semiestruturado com policiais e dirigentes da política de segurança no período compreendido entre 1990 e 2014.

\section{A institucionalização da participação no campo da segurança pública: o caso dos Consegs no Estado de São Paulo}

Os Consegs foram criados em São Paulo por meio do Decreto no 23.455/85, que define como seu objetivo colaborar no equacionamento e solução de problemas relacionados com a segurança da população. $\mathrm{O}$ documento estabelece que a base de sua atuação coincida com a área de cada Distrito Policial e Companhia de Policiamento da Capital, além 
de indicar quais são os atores que devem participar: autoridades policiais, representantes de associações, Prefeituras e outras entidades prestadoras de serviços relevantes à coletividade.

No ano de 1985, os Consegs foram regulamentados pela resolução SSP-37/85, e em 1986, a Secretaria de Segurança Pública (SSP) criou a figura do Coordenador Estadual dos Consegs ${ }^{3}$, na tentativa de prover maior institucionalidade e garantir a manutenção das instâncias participativas. Apesar dessa iniciativa, e do empenho do Governador Franco Montoro em ampliar a participação popular, os Consegs não se firmaram na estrutura organizacional da segurança pública. Na sequência, as gestões de Orestes Quércia e Luiz Antonio Fleury à frente do Executivo foram caracterizadas por políticas de segurança mais duras e pelo recrudescimento da criminalidade, o que inviabilizou o funcionamento dos conselhos.

Foi apenas em 1995, com a eleição de Mário Covas para o governo do Estado, que os Consegs tornaram-se estruturas regularmente em funcionamento. Covas tinha como projeto prioritário para a área da segurança o controle externo da atividade policial, e compreendia os conselhos como instância estratégica dessa política. Para garantir sua institucionalização criou um Grupo de Trabalho que contava com a participação do Núcleo de Estudos da Violência da USP, de membros das polícias e da Coordenadoria de Análise e Planejamento (CAP) da Secretaria de Segurança Pública. O GT tinha como objetivo promover alterações no regulamento dos Consegs. O novo documento ${ }^{4}$, que regeu os conselhos até 2013, tornou o regulamento de 1985 bem mais detalhado e favoreceu instrumentos de cobrança pela sociedade civil, embora, por pressão das polícias, não tenha tornado os conselhos espaços de controle externo aos abusos policiais (Galdeano, 2009). Também estabeleceu uma termino-

\footnotetext{
${ }^{3}$ Por meio do Decreto no $25.366 / 86$.

${ }^{4}$ Resolução SSP-47/99
} 
logia institucional que dá nome aos seus participantes: os delegados de polícia e os capitães da Polícia Militar responsáveis pela área circunscrita pelos Consegs são denominados membros natos, com a incumbência de articular a comunidade e os órgãos públicos para a correção de fatores que afetam a segurança pública; os membros efetivos são todos aqueles que não são membros natos, podendo-se tratar de participantes assíduos ou visitantes.

Os Consegs foram definidos então como canal privilegiado pelo qual a Secretaria da Segurança Pública auscultará a sociedade, contribuindo para que a Polícia Estadual opere em função do cidadão e da comunidade. Tinham, portanto, como uma de suas finalidades a proposição de prioridades na Segurança Pública na área circunscricionada pelo Consegs. Também foi definida a estrutura da diretoria dos conselhos, composta por Membros Natos; Presidente; Vice-Presidente; 1은 Secretário; 2o Secretário; e Diretor Social e de Assuntos Comunitários. O regulamento também estabeleceu condições mínimas para a realização de reuniões, bem como ritos que deviam ser seguidos em cada seção. Além disso, definia as regras para a eleição da diretoria, formação e dissolução do Conseg, contendo ainda disposições éticas e disciplinares.

Em 2002, o então governador Geraldo Alckmin enviou à Assembleia Legislativa um projeto de lei ${ }^{5}$ que tinha por objetivo fixar a origem dos Consegs em lei, substituindo tanto o decreto de criação dos Consegs quanto o decreto de criação do cargo de coordenador. Dois substitutivos foram apresentados, sendo um deles focado na transformação dos Consegs em instituição de controle externo da polícia. Diante desse quadro, o projeto original foi retirado pelo próprio Poder Executivo em junho de 2003. Apenas no início de 2005 o tema foi retomado, mas Alckmin apre-

${ }^{5} \mathrm{PL}$ no $579 / 2002$ 
sentou naquele momento um projeto bastante diferente, dessa vez com ênfase na estabilidade institucional da Coordenadoria. A Lei Complementar no 974 de 21 de setembro de 2005 criou, na estrutura básica da Secretaria de Segurança Pública, a Coordenadoria Estadual dos Conselhos Comunitários de Segurança, com oito cargos técnicos, mais o cargo de coordenador (Astolfi, 2014, pp. 45-46).

O regulamento exposto acima foi substituído por um novo texto em 2013, por advento da Resolução SSP-181/13, que revogou e substituiu a Resolução SSP-47/99. Em relação ao regulamento anterior, o novo trouxe algumas mudanças importantes, tais como a inclusão das categorias de Membros Institucionais Públicos, Membros Representativos e Membros dos Núcleos de Ação Local (NAL). Os Membros Institucionais Públicos são os representantes do Poder Público nos Consegs, com atribuições correlatas à segurança pública, como Ministério Público, Poder Judiciário e Legislativo, Prefeituras, Subprefeituras, Secretarias, Guardas Municipais, Conselho Tutelar, dentre outros. Por sua vez, os Membros Representativos são líderes de organizações não governamentais, tais como: entidades filantrópicas, OSCIPs, instituições religiosas e educacionais, entre outras de mesma natureza, bem como aqueles oriundos da iniciativa privada (...). Quanto ao Núcleo de Ação Local, trata-se de

uma célula de mobilização comunitária do Conseg nos bairros, vilas, distritos, áreas rurais ou micro comunidades de interesses ou afinidades específicas, e destina-se ao desenvolvimento de atividades de apoio ao Conseg a que se subordina para garantia de alcance e consecução dos objetivos estabelecidos neste Regulamento (Resolução SSP-181/13).

Cumpre notar que, ainda que esses membros tenham sido incluídos, a presença obrigatória é limitada aos Membros Natos. Entretanto, a Lei no 13.299 de 16/01/2002 estabeleceu que o Poder Executivo municipal 
será representado nas reuniões dos Conselhos Comunitários de Segurança mediante a participação de um servidor designado pela Administração Regional ou Subprefeitura da região a que pertencer o Conselho e um designado pela Guarda Civil Metropolitana.

Assim, a presença de representantes da Subprefeitura e da Guarda Municipal é a regra.

O novo regulamento também tornou mais sucinta a lista de finalidades dos Consegs. Uma das alterações mais importantes refere-se à exclusão do item Propor às autoridades policiais a definição de prioridades na Segurança Pública, na área circunscricionada pelo Conseg, na evidência de um certo estreitamento da noção de participação. Também foi excluído o item Colaborar supletivamente com o Poder Público na manutenção e melhoria de instalações, equipamento, armamento e viaturas policiais da área. Como novidade, o novo regulamento traz como uma das finalidades do Conseg a interação com

o Poder Público visando à prevenção e resolução de conflitos e demandas administrativas que repercutam diretamente no ambiente e fragilizam a segurança coletiva, tais como: iluminação, trânsito, problemas ambientais e sociais, ausência de fiscalização, alvarás, perturbação, áreas degradadas, entre outros, o que se relaciona à participação dos Membros Institucionais Públicos e Representativos.

A seção "Ética e Disciplina" do atual regulamento define como um dos deveres dos membros evitar o uso do Conseg e do NAL para proselitismo político-partidário, comercial ou religioso, o que nem sempre se observa na prática. São frequentes as reuniões em que vereadores e assessores de parlamentares comparecem e participam.

Em julho de 2014, através do Decreto 60.647/14, foi criado um Grupo de Trabalho para apresentar propostas para aperfeiçoamento dos Conselhos Comunitários de Segurança - Consegs e dos mecanismos de 
participação comunitária na execução da política de segurança pública do Estado de São Paulo. Como resultado desse trabalho, em novembro de 2014 o governador Geraldo Alckmin assinou o Decreto 60.873/14, que transforma os Consegs em fóruns para que a população acompanhe, em conjunto com as Polícias Civil e Militar, a execução do Plano de Metas em sua região ${ }^{6}$.

A reformulação dos Consegs inclui ainda a criação do portal Conseg Virtual, que divulgará as metas e as ações dos conselhos, de modo a meIhorar a comunicação entre a política pública e os cidadãos. Atualmente o Estado de São Paulo conta com 476 conselhos comunitários de segurança, dos quais 93 apenas no município de São Paulo - um para cada distrito policial da capital.

\section{Reflexões sobre a participação nos Conselhos Comunitários de Segurança}

As Instituições Participativas constituem uma forma relativamente nova de participação nas políticas públicas no Brasil. O conceito de instituições participativas surge a partir de crítica de Leonardo Avritzer (2008) ao modo como a ciência política trata do conceito de instituição política, privilegiando apenas os modelos formais de democracia representativa. $\mathrm{O}$ autor afirma que esse olhar tradicional da ciência política limita a análise de novos arranjos participativos em dois eixos: de um lado, a abrangência limitada do conceito desconsidera as novas práticas participativas ao trabaIhar apenas com as instituições que resultam do processo de autorização da representação; de outro, a abordagem clássica da ciência política é incapaz de captar o sentido dessas novas modalidades, que não estão formalmente

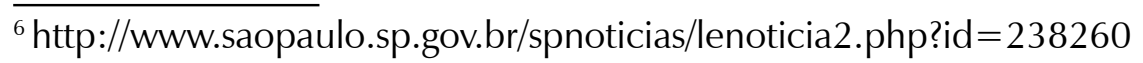


definidas. Avritzer destaca ainda que a representação realizada por atores da sociedade civil é diferente da representação no Parlamento, por não existir o requisito explícito da autorização, estrutura de monopólio territorial e tampouco um suposto de igualdade matemática (2007). Ou seja, a representação via sociedade civil assume um caráter pluralista e, mesmo que ocorra nos limites de um determinado território a partir de uma estrutura de conselho, também coincide com outras instâncias.

Um dos objetos de análise de diversos pesquisadores Brasil afora tem sido compreender os resultados produzidos pelas instituições participativas. Wampler (2011) afirma que, embora diversos estudos apontem que as IPs tenham promovido mudanças significativas nas formas de deliberação com a ampliação da participação social, incremento da capacidade política dos cidadãos e mudanças nos tipos de políticas públicas ofertadas pelos governos (Dagnino; Oliveira; Panfichi, 2006; Avritzer, 2009), é forçoso admitir que parte da literatura tende a reconhecer os limites das instituições participativas em produzir mudanças nas políticas públicas.

Luciana Tatagiba e Ana Cláudia Teixeira (2006) analisam a participação social na gestão da então petista Marta Suplicy na prefeitura de São Paulo (2001-2004) e afirmam que, embora esta tenha sido marcada pela ampliação dos canais de participação por meio de vários processos, como o Orçamento Participativo e os Planos Diretores, não foi capaz de investir nesses canais reconfigurando a forma de governabilidade. Pelo contrário, a experiência de democracia participativa conviveu com práticas de gestão extremamente conservadoras, forjada em relações de trocas e interesses eleitoreiros. Como resultado, a participação acabou por assumir um caráter instrumental, estratégico para o governo, de modo que não impactou na lógica de funcionamento das instituições públicas.

Na mesma direção, Mário Fuks, Renato Perissinotto e Nelson Souza (2004) concluem, em análise dos conselhos gestores de políticas públicas 
no Paraná, que a proposição e definição dos temas nesses espaços ocorrera de acordo com os interesses do Estado, sem qualquer tipo de debate ou negociação com a sociedade civil. Consequentemente, a participação tornou-se branda, desprovida de perspectiva crítica em relação ao papel do Estado e, apesar de inovar em estratégias gerenciais, não alterou o modo pelo qual as políticas públicas eram definidas.

Não à toa, as análises sobre participação social e instituições participativas no campo da segurança também têm sido marcadas por fortes críticas. Para Simões (2009), a participação popular no campo da segurança pública simplesmente inexiste, sendo marginal, periférica, irrelevante (p. 45). O autor afirma que a presença popular na política de segurança pública assumiu três formas tradicionais, argumento corroborado por Martins (2013, p. 204). As três condições em que a sociedade civil e os cidadãos participam das políticas de segurança pública são: i) condição de suspeitos e eventuais réus em processos criminais; ii) condição de informantes, de colaboradores da polícia para fornecer informações e levar denúncias; e iii) contribuintes para sanar a precariedade material enfrentada pelas polícias e para arrecadar recursos (Simões, 2009, apud Martins, 2013). Segundo Alan Fernandes (2014), embora o fator que tenha motivado a criação dos Consegs tenha sido o ideal participativo de construção comunitária, essas estruturas configuram hoje mais um "balcão" de demandas, no qual os cidadãos podem encaminhar suas reclamações, não constituindo instâncias capazes de garantir a participação contínua do cidadão.

De maneira comum, os autores citados expressam as dificuldades de mudanças nos padrões de relacionamento entre polícia e sociedade, tornando a participação social um tema marginal. Não obstante a nova ordem constitucional constituir um marco no que diz respeito à ampliação da participação popular enquanto mecanismo fundamental das políticas públicas, a Constituição Federal de 1988 em nada avançou no que 
diz respeito à arquitetura institucional das polícias e do sistema de segurança pública, de modo que práticas institucionais continuaram vigentes, não sendo capazes de transformar a relação entre seus operadores e a população.

Diante desse argumento, o primeiro ponto a ser destacado diz respeito ao protagonismo exercido pela Polícia Militar (PM) nas reuniões dos Consegs. Se essas instâncias foram criadas na década de 1980 por delegados da Polícia Civil, e apesar de verificarmos a presença de policiais das duas corporações em todas as 35 reuniões acompanhadas, na prática são os policiais militares que dão o tom e a dinâmica das reuniões, fator decisivo para compreender a qualidade da participação nesses espaços.

É necessário reconhecer que as reuniões ocorrem mensalmente e funcionam como ponte entre a população, as polícias e os gestores de outras políticas setoriais. Percentual significativo dos tópicos de discussão relaciona-se a questões de manutenção do espaço urbano e não necessariamente problemas de polícia, tais como iluminação, limpeza e pavimento de ruas. Já as pautas relacionadas diretamente a atuação policial variam de acordo com a localização do Conseg: enquanto no Conseg Heliópolis a principal questão são os roubos e os bailes funks ("pancadões"), no conseg Itaim os problemas dizem respeito ao roubo de relógios Rolex e à presença de moradores de rua e pedintes na região.

As pautas relacionadas diretamente à atividade policial em geral expressam reclamações derivadas da percepção da população de que o crime está crescendo, e demandam, invariavelmente, mais policiamento. Cumpre ressaltar, no entanto, que as críticas toleradas nesses espaços restringem-se à criminalidade que assola o bairro, e nunca à ação das polícias. Quando a crítica ao trabalho policial ocorre de forma mais contundente, em geral é prontamente rechaçada pelo policial da reunião. 
Em uma reunião, por exemplo, duas moradoras queixaram-se sobre os frequentes assaltos na região, e uma delas afirmou que a polícia não estaria fazendo nada para conter a criminalidade. Diante de sua fala exaltada, o tenente à mesa respondeu de forma ríspida e defensiva, afirmando que a população só sabe reclamar da polícia, sem levar em conta as dificuldades enfrentadas pelos policiais. Antes de a senhora responder, o presidente da mesa anunciou a presença de um vereador, coronel da reserva da PMESP, e disse que daria a palavra a ele antes que a população pudesse fazer suas perguntas. A senhora reclamou publicamente, perguntando Quando é que vamos poder falar?. Sua reclamação não foi registrada, e a discussão entre moradores e tenente foi suavizada no registro da ata.

Outro exemplo ocorreu diante da reclamação de uma moradora, que alegou que a PM tinha usado de spray de pimenta na repressão a um baile funk $\mathrm{k}^{7}$. O capitão da PM respondeu à moradora afirmando já ter sido baleado na comunidade, e que não hesitaria em usar o spray de pimenta ou sua arma de fogo. Ao final da reunião, a mulher pediu desculpas para o tenente, ressaltando que ele era nervosinho. O policial prontamente respondeu que como um homem macho e viril, não aceita que um homem grite com ele, muito menos uma mulher. A mulher ficou em silêncio e se retirou.

Os casos relatados são emblemáticos do constrangimento a que os cidadãos são submetidos quando tentam oferecer qualquer tipo de crítica ao trabalho policial. Na visão dos policiais que fazem a gestão das reuniões, e corroborando os argumentos de Martins (2013) e Fernandes (2014), o morador que frequenta o Conseg tem como dever prestar informações ao policial, mas não lhe cabe questionar ou tentar interferir na condução do trabalho das polícias.

\footnotetext{
${ }_{7}$ Popularmente chamados de "pancadões".
} 
Outro desdobramento importante do protagonismo da Polícia Militar nos Consegs são os mecanismos utilizados para ratificação de suas ações nos territórios. Em uma ocasião, o policial militar colheu depoimentos dos moradores sobre os "pancadões", esclarecendo que precisava de declarações gravadas para justificar qualquer ação repressiva. Segundo o policial, esse tipo de operação resulta em muitas reclamações de pessoas machucadas na Corregedoria. Os policiais orientaram os moradores a deslocarem-se à Corregedoria a fim de apoiá-los, uma vez que ligar não é o bastante. De maneira complementar, um policial afirmou que a questão dos bailes funk teria solução, mas que isso dependeria do governo: é só liberar o Choque, é só deixar as pessoas apanhando um mês para ver se elas não param, o que foi prontamente apoiado pelos participantes. Outra fala comumente ouvida dos policiais foi que a polícia está de mãos atadas, impedida de atuar.

Garantir que as reuniões sejam espaços acríticos e ratificadores da ação policial implica em garantir também que os participantes coadunem com o jogo. Nesse sentido, argumentamos que a polícia militar não assume protagonismo apenas na condução das reuniões, mas também na definição de quem pode participar. Um exemplo emblemático dessa seletividade ocorre durante a discussão sobre como administrar os bailes funk. Em determinada ocasião, o presidente da mesa afirmou que em encontros anteriores existiam infiltrados que levavam as discussões das reuniões aos moradores da comunidade, informando sobre as reclamações dos "pancadões". Preocupado com o fato, o mesmo pediu que, caso alguém identificasse um X-9 ou leva-e-traz ali, deveria avisá-lo. Em outra ocasião um senhor tentou filmar a reunião e o capitão o interpelou. $\mathrm{O}$ senhor disse que não faria nada com aquele vídeo e que também estava ali para reclamar do funk, ao que o capitão afirmou que tinha medo que aquele vídeo caísse em mãos erradas. 
Os relatos apresentados são a evidência empírica de que os conselhos comunitários de segurança configuram estruturas que reproduzem relações hierárquicas e assimétricas entre polícia e sociedade, não se traduzindo em instâncias plurais de construção da política pública. Pelo contrário, configuram espaços que servem para garantir a legitimidade e a estabilidade organizacional da PM. Ao cooptarem esses espaços participativos, nos termos do que propõe Sezlnick (1953), a PMESP encontrou um mecanismo de ratificar as ações policiais e retroalimentar práticas institucionalizadas.

Entendemos cooptação como o processo de absorção de novos elementos à liderança ou à estrutura de determinação das políticas de uma organização como um meio de evitar ameaças para sua estabilidade ou sua existência (Selznick, 1953, p.13) ${ }^{8}$. Podemos diferenciar a cooptação informal de uma cooptação formal, em que mecanismos institucionais são criados. O que está em jogo na avaliação da cooptação é se há realmente uma divisão de poder: cooptation which results in an actual sharing of power will tend to operate informally, and correlatively, cooptation oriented toward legitimization or accessibility will tend to be effected through formal devices (p. 136). Ambas podem coexistir, e a dimensão informal pode servir para uma retroalimentação das próprias instâncias formais criadas para a estabilidade organizacional.

O conceito oferece pistas analíticas para pensar a apropriação dos espaços dos Consegs pela PMESP. A saída para a carência de legitimidade da polícia entre a população foi a manutenção de espaços de participação formal, sem a abertura para controle externo ou uma real partilha de poder, mas suficiente para alçar essa legitimidade. Essa análise aproxima-se do argumento de Loche (2012), para quem a implementação do policiamento comunitário no Estado de São Paulo na década de 1990 foi,

\footnotetext{
${ }^{8}$ Tradução de: "the process of absorbing new elements into the leadership or policy-determining structure of an organization as a means of averting threats to its stability or existence".
} 
sobretudo uma tentativa de recuperar a imagem da polícia, desgastada pelos sucessivos escândalos de violência. Partindo da teoria da adaptação de Garland (2008), a autora afirma que as estratégias desenvolvidas pela PM paulista estavam associadas a uma adaptação pragmática das agências policiais à nova realidade. Mais do que o resultado de escolhas administrativas relacionadas à eficiência da polícia, sua adoção relacionou-se com a manutenção e legitimidade da instituição (Bueno, 2014).

\section{Participação para quem? Cidadão de bem versus vagabundo}

As reflexões apresentadas na seção anterior evidenciaram os mecanismos utilizados pelas autoridades públicas para controlar a participação nos conselhos comunitários de segurança, definindo as pautas discutidas, legitimando as ações das polícias, mas também influenciando em quem pode participar desses espaços. Esse fator é, talvez, um dos principais pontos a serem destacados por esta pesquisa, já que determina fundamentalmente o potencial de ação desses espaços enquanto canais plurais ou não de participação popular.

A literatura aponta que os conselhos comunitários de segurança constituem espaços que mobilizam esquemas de significação da violência que articulam preconceitos de classe, ocupação social, gênero, etnicidade, dentre outros. Como bem afirma Galdeano (2009), esses encontros geralmente são marcados por relações intolerantes e discursos pautados na segregação política e no aprofundamento de esquemas de diferenciação social, nos quais a "linguagem dos direitos" tende a se mesclar a discursos que negligenciam o direito dos outros. Galdeano afirma ainda que não se trata de uma questão de classe social, mas que moradores de todas as classes parecem acionar explicações duais ao manifestar as demandas por seus direitos específicos. 
Considerando as dinâmicas dos conselhos estudados, verificamos que, via de regra, as reuniões são marcadas por discursos intolerantes e que reforçam preconceitos, independente das especificidades locais e do perfil dos participantes. Desse modo, não se trata de esquemas de significação pautados na distinção de classe social, mas acionados a partir da categoria "cidadãos de bem", para usar a categoria nativa. Não à toa, a Cartilha de Policiamento Comunitário da Polícia Militar do Estado de São Paulo, datada de 2007, afirma que:

É de fundamental importância o entendimento de que os preceitos doutrinários de policiamento comunitário visam ao atendimento dos cidadãos de bem, pois aos infratores da lei e arredios às regras sociais se aplicam as normas e a legislação vigentes. Ressalte-se que policiamento comunitário não se traduz em forma branda de aplicabilidade legal, mas sim, atuação de uma polícia voltada à cidadania e, essencialmente, participativa (Cartilha de Policiamento Comunitário da Polícia Militar do Estado de São Paulo, 2007).

Como se apreende do trecho em destaque, o manual redigido pela corporação e distribuído ao público compreende que os preceitos doutrinários do policiamento comunitário, cujos Consegs são um dos principais pilares, devem ser aplicados única e exclusivamente aos cidadãos de bem, embora a própria cartilha não defina o que vem a ser o "cidadão de bem". Na ausência de uma definição mais clara acerca do que vem a ser esse conceito, ele vai sendo definido e redefinido no dia a dia da atividade policial e pelos próprios moradores.

A partir dos enunciados de policiais e moradores, é possível supor que aquele que não faz parte da categoria cidadão de bem é o sujeito que rompe com a noção de ordem e boa conduta, e que deveria, portanto, ter seus direitos relativizados, geralmente associado à categoria "vagabundo". No Conseg Butantã o "vagabundo" é o ladrão, aquele que aumenta os índices de criminalidade da região, bem como o participante do baile 
funk; no Conseg Itaim Bibi essa categoria foi associada aos moradores de uma favela recém construída, o que gerou diversas reclamações dos moradores que argumentaram que a favela não se adequava ao "conceito do bairro"; em Heliópolis, os frequentadores dos chamados "pancadões" foram sempre associados ao crime, sendo numerosos os pedidos dirigidos à polícia para que eles fossem tratados com violência; no Conseg Santa Cecília, a associação dos usuários de crack e moradores de rua a um comportamento marginal e criminoso foi feita reiteradamente, quer fosse pelos frequentadores, quer fosse pelos policiais.

O elemento comum aos discursos ouvidos em cada um desses Consegs é o da criminalização de determinadas condutas, o que seria traduzido numa exclusão de cidadania de determinados segmentos, ao passo em que o tratamento dispensado a esse grupo não deveria ser o mesmo que o dispensado ao cidadão de bem. O cidadão de bem é aquele que merece a cidadania, a política pública, o tratamento educado do policial, o que tem o direito de participar. Aquele que não faz parte dessa categoria representa um elemento perigoso, que vem de espaços marginais, polui e contamina (Caldeira, 2000). O cidadão de bem seria tradução, pós-crises econômicas da década de 1980, da categoria "trabalhador", tão bem analisada pelos estudos de Alba Zaluar (1985). Se, nos anos 1980, vigorava o binômio "trabalhador" x "vagabundo", agora temos o "cidadão de bem" x "vagabundo", numa atualização dessas categorias frente às transformações socioeconômicas e demográficas vivenciadas pela população brasileira nas últimas décadas.

Em determinada reunião, uma senhora agradeceu a polícia pela limpeza feita na região da cracolândia, afirmando que a polícia não está podendo ajudar como ela queria. Mostrou-se indignada com os moradores de rua, a quem dirigiu inúmeras acusações: eles são os donos, nós não, eu que pago imposto... quero que alguém esclareça como eu vou 
resolver a minha rua. A senhora reclamou ainda dos bares, e também dos ambulantes: tem um camelô que está todo dia lá, não sei o que ele vende, mas lá só tem nóia, e ele não tem licença. Por fim, perguntou se a base móvel da PM que seria colocada no Largo Coração de Jesus só atenderia os moradores ou se também faria uma limpeza na área, removendo os usuários de droga.

Em outra ocasião, o presidente afirmou que estes políticos só veem a violência e truculência da polícia com os moradores de rua, mas não a violência e truculência dos moradores de rua contra o cidadão de bem. Fez ainda acusações à Defensoria Pública: Os defensores públicos, sabe-se lá Deus a quem estão associados, estão contribuindo para transformar a cidade nisso; disse que essas minorias se transformaram em verdadeiras tribos, culpando os que dão comida, alimentando essa gente pela manutenção da miséria humana. Uma senhora pede a palavra e responde ao presidente: O Conseg deveria se reunir para fazer um mutirão contra os direitos humanos, ao que o presidente responde: sentimos sua falta na última reunião. A senhora é uma pérola na nossa reunião.

Como exposto, diversos são os relatos fundados na dicotomia entre o "cidadão de bem" e o "vagabundo". Para Cardia (1995), os fundamentos ideológicos dessa distinção se encontram na ideia de mérito e de proporcionalidade da justiça - ou seja, de que a justiça deve funcionar para o "cidadão de bem" enquanto os "criminosos" devem ser sumariamente eliminados por não "merecerem" direito a defesa e sim uma exclusão moral:

(...) o apoio às graves violações do direito à vida e à pena de morte derivam da exclusão dos presos, dos suspeitos, ou ainda das vítimas de violência policial, do mundo moral deste grupo que apoia as graves violações. Este grupo apresenta vários indícios de ter normalizado o uso da violência por parte da polícia: não considera grave o uso de tortura ou as mortes pela polícia, apesar de serem frequentes; con- 
corda que a polícia bata em presos ou porque é uma forma de punição, ou porque é a única forma de confessarem; é contra o governo acabar com os esquadrões da morte e com os justiceiros; e, por fim, alguns deles defendem a pena de morte por que 'bandido tem que morrer'. (...) A negação de direitos aos presos é um dos indicadores da exclusão moral... quem está fora da comunidade moral ou opõe-se a esta comunidade não evoca injustiça, isto é, a exclusão moral - a negação da injustiça. Nestas condições, para aqueles que excluem, não há danos ou maus tratos que possam ocorrer porque quaisquer danos/maus tratos são justificados ou são merecidos" (p. 63).

Em suma, os dados apresentados evidenciam as dificuldades de a sociedade brasileira desvencilhar-se de suas históricas estruturas autoritárias e violentas e deixar que o cidadão usufrua de amplos direitos, com liberdade, participação e acesso à Justiça, tal como previsto no nosso marco legal (Lima; Sinhoretto; Bueno, 2015). A criação de espaços de participação social no campo da segurança pública não se traduziu diretamente em espaços democráticos e plurais, e sim em estruturas que nos fazem lembrar das contradições de uma democracia incapaz de garantir cidadania a todos os grupos sociais.

\section{Conclusão}

Instituições participativas têm sido descritas pela literatura como espaços capazes de mitigar tradicionais desigualdades políticas pela suposição de que constituem canais de participação para grupos tradicionalmente marginalizados dos processos decisórios (Alencar et al, 2013). Em tese, constituiriam ambientes plurais de participação no qual o cidadão, sujeito de direitos, participaria coletivamente da construção da política pública. 
Analisando o caso da segurança pública, é forçoso reconhecer que os conselhos comunitários constituem as estruturas mais visíveis de participação popular na segurança pública do Estado de São Paulo e, mais do que isso, encontram-se em funcionamento e institucionalizados. Contudo, estão longe de constituírem instâncias plurais ou de estimular a cultura da prevenção criminal e da contenção da violência, como prevê seu regulamento. Em sentido oposto, as dinâmicas observadas demonstram que esses espaços têm sido marcados pela reprodução de desigualdades políticas e sociais, transformando o ideal do "sujeito de direitos" em mero demandante da política pública.

Em que pese atualmente os Consegs estarem inseridos dentro do rol de ações da estratégia de policiamento comunitário, um dos três eixos prioritários da atuação da Polícia Militar de São Paulo desde 1997, esses espaços têm sido geridos com o propósito de legitimar as práticas da instituição nos territórios, e não necessariamente com o objetivo de estreitar laços entre polícia e comunidade. Verifica-se, portanto, que os Consegs funcionam menos como espaços nos quais a população fiscaliza a ação do poder público, e mais como instâncias que ratificam a ação policial e cujas demandas dos moradores são expressas.

Efeito direto da forma como a polícia se apropria desses espaços, na prática os conselhos configuram espaços de diálogo entre determinados segmentos da população, o cidadão de bem, e o poder público. A Polícia Militar estaria a operar um modelo participativo que, ao invés de democratizar o Estado, recompõe e retroalimenta a legitimidade de práticas institucionais e culturas organizacionais pautadas na violência e na exclusão; na ideia de que o enfrentamento da violência passa menos pela modernização dos mecanismos de controle do crime, e mais pela eliminação do criminoso e do vagabundo. $E$, nesse processo, a relação entre polícia e comunidade; entre Estado e sociedade, configura-se como 
hierárquica e assimétrica, na medida em que os Consegs têm, segundo as observações feitas, um caráter instrumental que envolve acesso a informações e apoio ativo na validação do sentido/padrão do serviço prestado pelas corporações policiais, sobretudo a Polícia Militar. As polícias aceitam a participação desde que ela não interfira na determinação do padrão de atuação e não questione as opções institucionais vigentes, que são tributárias de uma série de movimentos históricos e políticos mais bem narrados por Bueno (2014). E, mesmo assim, a escuta depende de um filtro simbólico sobre quem merece ser "cidadão de bem" e quem deve ser considerado "vagabundo", ou seja, de quem, pelo imaginário social, deve ser o sujeito de direitos.

No limite, as polícias estariam a operar um poderoso instrumento de determinação de fronteiras entre o legal e o ilegal; entre aquilo que pode ser moralmente aceito ou não, independentemente da norma legal. Há um esforço muito grande de repor continuamente a legitimidade da ação policial e as reuniões do Conseg fariam parte dessa estratégia. Os Consegs seriam a tradução de que a participação social foi aceita como mecanismo de modernização da segurança pública, mas na perspectiva de mudar para manter tudo como está, à semelhança da máxima de "O Leopardo", de Tomaso de Lampedusa.

Samira Bueno: Doutoranda em Administração Pública e Governo pela FGV EAESP. Diretora Executiva do Fórum Brasileiro de Segurança Pública.

$\triangle$ samibueno@gmail.com

Renato Sérgio de Lima: Doutor em Sociologia (2005) pela Universidade de São Paulo. É Professor da FGV EAESP e Pesquisador do Centro de Pesquisas Jurídicas Aplicadas da FGV Direito SP - CPJA. Vice Presidente do Conselho de Administração do Fórum Brasileiro de Segurança Pública.

$\triangle$ renato.lima@forumseguranca.org.br 
Marco Antonio Carvalho Teixeira: Professor da FGV EAESP. Coordenador Adjunto do Curso de Graduação da FGV EAESP. $\$ marco.teixeira@fgv.br

\section{Bibliografia}

1. ALENCAR, J. et al. Participação social e desigualdades nos conselhos nacionais. Sociologias, Porto Alegre, v. 15, n. 32, 2013, p. 112-146.

2. ASTOLFI, R. C. Povo e polícia, uma só direção: os estreitos canais de participação dos Conselhos Comunitários de Segurança da cidade de São Paulo. Dissertação de mestrado. Universidade de São Paulo, Faculdade de Filosofia, Letras e Ciências Humanas: 2014.

3. AVRITZER, L. "Sociedade Civil, Instituições Participativas e Representação: Da Autorização à Legitimidade da Ação". In: DADOS - Revista de Ciências Sociais, Rio de Janeiro, vol. 50, no 3, 2007, pp. 443-464.

4. AVRITZER, L. Instituições participativas e desenho institucional: algumas considerações sobre a variação da participação no Brasil democrático. Opinião Pública, Campinas, vol. 14, no 1, Junho, 2008, p.43-64

5. AVRITZER, L. Participatory institutions in democratic Brazil. Washington: Woodrow Wilson Center Press and The John Hopkins University Press, 2009.

6. BUENO, S. Bandido bom é bandido morto: a opção ideológico-institucional da política de segurança pública na manutenção de padrões de atuação violentos da polícia militar paulista. Dissertação de Mestrado. Fundação Getúlio Vargas, Escola de Administração de Empresas de São Paulo: 2014.

7. CALDEIRA, T. P. Cidade de muros: crime, segregação e cidadania em São Paulo. São Paulo: Editora 34, Edusp; 2000.

8. CARDIA, N. Direitos Humanos: ausência de cidadania e exclusão moral. São Paulo: Comissão de Justiça e Paz, 1995.

9. CARTILHA de Policiamento Comunitário: Procedimentos Operacionais. 2007. 1‥ Edição.

10. CARVALHO, J.M. Cidadania no Brasil: o longo caminho. 1. ed. Rio de Janeiro: Civilização Brasileira, 2001. v. 1.

11. DAGNINO, E.; OLIVEIRA, A.; PANFICHI, A. (org.) A disputa pela construção democrática na América Latina. São Paulo: Paz e Terra, 2006. 
12. FERNANDES, A. Violência e gestão da ordem social em Furnas-Tremembé. Dissertação (mestrado em Ciências Sociais) - Universidade Federal de São Paulo, Escola de Filosofia, Letras e Ciências Humanas, 2014.

13. FUNG, A.; WRIGHT, E. O. Deepening democracy: innovations in empowered participatory governance. In: Politics and Society, no 29, 2001, p. 5-42.

14. FUKS, M.; PERISSINOTTO, R.M.; SOUZA, N.R.(orgs.). Democracia e participação: Os conselhos gestores do Paraná. Curitiba: UFPR, 2004.

15. GALDEANO, A.P. Para falar em nome da segurança: o que pensam, querem e fazem os representantes dos Conselhos Comunitários de Segurança. Tese de Doutorado. Universidade Estadual de Campinas, Instituto de Filosofia e Ciências Humanas: 2009.

16. GARLAND, D. A Cultura do Controle: Crime e Ordem Social na Sociedade Contemporânea. Rio de Janeiro: Revan, 2008.

17. LIMA, R.S.de; SINHORETTO, J.; BUENO, S. A gestão da vida e da segurança pública no Brasil. Soc. estado, Brasília, v. 30, n. 1, p. 123-144, Apr. 2015.

18. LOCHE, Adriana Alves. Segurança e controle social: uma análise do policiamento comunitário. 2012. Tese (Doutorado em Sociologia) - Faculdade de Filosofia, Letras e Ciências Humanas, Universidade de São Paulo, São Paulo, 2012. Disponível em: <http://www.teses.usp.br/teses/disponiveis/8/8132/tde08112012-171148/> . Acesso: 2016-06-02

19. MARSHALL, T.H. Cidadania, classe social e status. Rio de Janeiro: Zahar, 1967.

20. MARTINS, L. P. B. Participar é preciso: uma discussão sobre cidadania e participação social no campo da segurança pública. In: Confluências: revista interdisciplinar de Sociologia e Direito. vol. 15, no 2, 2013. pp. 179-217.

21. O'DONNELL, G. Accountability horizontal e novas poliarquias. Lua Nova: Revista de Cultura e Política, São Paulo, CEDEC, n. 44, p. 27-103, 1998.

22. SADER, Eder. Quando novos personagens entram em cena: experiências, falas e lutas dos trabalhadores da Grande São Paulo (1970-80). São Paulo: Paz e Terra, 1988.

23. SANTOS, W. G. dos. Crise e Castigo: Partidos e Generais na Política. Rio de Janeiro, Vértice, 1987.

24. SELZNICK, P. TVA and the Grassroots - a study in the Sociology of formal organization. Berkeley and Los Angeles: University of California Press, 1953. 
25. SIMÕES, R. Segurança Pública e Participação Popular: uma avaliação. In: Cadernos Temáticos da CONSEG: Movimentos Sociais e Segurança Pública: a construção de um campo de direitos, Ano 01, no 09, Ministério da Justiça, Agosto de 2009.

26. TATAGIBA, L.; TEIXEIRA, A.C. Participação e democracia: Velhos e novos desafios. Civitas - Revista de Ciências Sociais, v. 6, n. 1, jan./jun. 2006, p. 223-240.

27. WAMPLER, B. Que tipos de resultados devemos esperar das instituições participativas? In: PIRES Roberto R. C. Efetividade das instituições participativas no Brasil: estratégias de avaliação. Brasília: Ipea, 2011.

28. ZALUAR, A. A máquina e a revolta. São Paulo: Brasiliense, 1985.

\section{Portarias/Legislação}

Decreto n. 54.911 (2009), que regulamentou a Lei Complementar n. 1036.

Resolução SSP-37/85, que regulamenta a existência dos CONSEGs

Decreto no 23.455/85, que cria os CONSEGs.

Decreto no 25.366/86, que cria o Coordenador Estadual dos CONSEGs.

Lei Complementar no 974/2005, que cria a Coordenadoria Estadual do CONSEGs.

Resolução SSP-47/99, que regulamenta os CONSEGs.

PL no 579/2002, que objetivava dar estabilidade institucional aos CONSEGs.

Lei Complementar no 974/2005, que criou Coordenadoria Estadual dos Conselhos Comunitários de Segurança.

Resolução SSP-181/13, que revogou e substituiu a Resolução SSP-47/99.

Lei $n$ o $13.299 / 2002$, que estabelece como regra a presença de um representante do GCM.

Lei $\mathrm{n}$ o 13.299 de 16/01/2002, que criou grupo de trabalho para aperfeiçoamento dos CONSEGs.

Decreto 60.873/14, que transformou os CONSEGs em Fóruns.

Recebido em: 02/06/2015

Aceite Final: 30/01//2016 